\title{
Matrix Metalloproteinases as Biomarkers of Endometriosis and the Role of Progesterone Receptors
}

\author{
Isabelle Baptista ${ }^{1}$, Ping Xia ${ }^{2}$ and Bhuchitra Singh ${ }^{1 *}$ \\ ${ }^{1}$ Division of Reproductive Sciences \& Women's Health Research, Department of Gynecology \& Obstetrics, Johns Hopkins \\ University, USA
}

${ }^{2}$ Division of Reproductive Endocrinology and Infertility, Department of Obstetrics and Gynecology, USA

*Corresponding author: Bhuchitra Singh, Division of Reproductive Sciences \& Women's Health Research, Department of Gynecology \& Obstetrics, USA

\begin{tabular}{|c|c|}
\hline ARTICLE INFO & ABSTRACT \\
\hline Received: 跳 September 20, 2019 & Endometriosis is a prevalent gynecological disorder that affects around 1 in 10 \\
\hline Published: September 30, 2019 & $\begin{array}{l}\text { women during their reproductive years. Typically, it is diagnosed by means of a pelvic } \\
\text { exam due to the lack of a non-invasive diagnostic method. However, in recent years, there }\end{array}$ \\
\hline $\begin{array}{l}\text { Citation: Isabelle B, Ping X, Bhuchitra S. } \\
\text { Matrix Metalloproteinases as Biomarkers of } \\
\text { Endometriosis and the Role of Progesterone } \\
\text { Receptors. Biomed J Sci \& Tech Res 21(4)- } \\
\text { 2019. BJSTR. MS.ID.003636. }\end{array}$ & $\begin{array}{l}\text { biomarkers of endometriosis. The aim of this review is to identify studies which reported } \\
\text { findings regarding the correlation between MMP expression and the pathogenesis of } \\
\text { endometriosis. Additionally, differential expression of two progesterone receptors may } \\
\text { be responsible for these abnormal expression of specific matrix metalloproteinases, } \\
\text { thus leading to the discussion of drug therapy as a possible treatment method of } \\
\text { endometriosis. }\end{array}$ \\
\hline
\end{tabular}

\section{Introduction}

Endometriosis is a gynecological disorder that affects around $10 \%$ of reproductive aged women. It occurs when endometrial tissue grows outside the uterus, and as the tissue thickens, sheds, and bleeds along with all endometrial tissue during menstruation, it cannot exit the body due to its displacement. Some women develop cysts (endometriomas). These symptoms can cause pain especially during menstruation and excessive bleeding. Women with endometriosis sometimes develop problems with fertility. There have been a multitude of research studies done in an effort to identify the biomolecules associated with this disease. The plethora of studies conducted have led to the recognition of biomolecules with abnormal expression levels in women with endometriosis, but they have also led to the scattering of different biomolecules among papers and the indecisive correlations between specific biomarkers and the disease [1]. There has been a failure to identify novel biomarkers that can be utilized in confidently identifying endometriosis. This hinders the ability to make a diagnosis noninvasively since the current methods to identify endometriosis include pelvic exams to locate cysts or scars. Recent research studies suggest a correlation between abnormal expression of Matrix Metallo Proteinases (MMPs) and endometriosis. MMPs

are "enzymes that mediate normal tissue turnover including endometrial breakdown at menstruation" [1]. The aim of this review is to discuss the results of these studies regarding the association between MMP expression and the pathogenesis of endometriosis to provide a starting point for further research in developing a non-invasive approach to recognizing endometriosis. Additionally, there is currently no reliable cure for the disease since surgical approaches may still cause recurrence. With the advances of the medical knowledge regarding the role of MMPs in endometriosis, it may become more feasible to start considering non-invasive treatments such as pharmacological approaches that target the factors mechanistically responsible for the unusual expression of these proteins.

\section{Materials and Methods}

A number of studies that investigated the role of MMPs in endometriosis were identified by searching for the keywords "MMPs" and "endometriosis" on pubmed.gov. This review addresses the results of these studies in order to explore the role of MMPs in the development of endometriosis and the possibility of using MMPs as non-invasive diagnostic biomarkers of endometriosis. Additional literature search was conducted via Pubmed utilizing the 
keywords "progesterone receptors," "SPRMs," and "endometriosis" in order to find the association of progesterone receptor expression with the disease's pathogenesis, as well as research done on class of, specific progesterone receptor modulators, and its potential in treating endometriosis.

\section{Results}

\section{MMPs and Invasion of Endometrium Tissues}

A review by Balkowiec et al. stated that "aberrant regulation of matrix metalloproteinases may be the primary cause of endometrial lesion formation" since their abnormal expression can lead to "adhesion formation, ovulatory disfunction and fertility impairment" [2]. Normally, Reversion-inducing-cysteine-rich protein with Kazal motifs (RECK) and Tissue Inhibitors of Metallo Proteinases (TIMPs) are responsible for regulating MMP activity, forming inhibitory complexes with specific catalytic regions on MMPs to contribute in Extra Cellular Matrix (ECM) remodeling, regulating angiogenesis and inflammatory reactions [2]. Table 1 summarizes all the studies.

Table 1: Endometriosis and MMP Levels.

\begin{tabular}{|c|c|c|c|c|c|c|c|c|}
\hline Study & Year & Ethnicity & MMP & $\begin{array}{c}\text { Experimental } \\
\text { Group Sample } \\
\text { Size }\end{array}$ & $\begin{array}{c}\text { Control } \\
\text { Group } \\
\text { Sample Size }\end{array}$ & $\begin{array}{c}\text { Sample Type } \\
\text { Experimental } \\
\text { Group MMP } \\
\text { Levels }\end{array}$ & $\begin{array}{c}\text { Control Group } \\
\text { MMP Levels }\end{array}$ \\
\hline Szamatowicz & 2002 & Caucasian & MMP-9 & 22 & 21 & $\begin{array}{c}\text { Serum } \\
6.2+/-1.8 \mathrm{ng} / \\
\mathrm{mL}\end{array}$ & $\begin{array}{c}2.9+/-2.6 \mathrm{ng} / \\
\mathrm{mL}\end{array}$ \\
\hline Haiping & 2015 & Asian & MMP-9 & 100 & 50 & Serum & $\begin{array}{c}6.42+/-0.53 \\
\mathrm{mM}\end{array}$ & $\begin{array}{c}1.21+/-0.51 \\
\mathrm{mM}\end{array}$ \\
\hline Bostanci & 2019 & Caucasian & MMP-9 & 60 & 31 & Serum & $15.0 \mathrm{pg} / \mathrm{mL}$ & $12.0 \mathrm{pg} / \mathrm{mL}$ \\
\hline Huang & 2004 & Asian & MMP-2 & 40 & 18 & Serum & $38.5+/-4.0 \mathrm{pg}$ & $19.8+/-4.7 \mathrm{pg}$ \\
\hline Malvezzi & 2013 & Multi-Ethnic & MMP-2 & 10 & 10 & Serum & $\begin{array}{c}\text { MMP-2 levels } \\
\text { higher in stages } \\
\text { III/IV vs stages } \\
\text { I/II }\end{array}$ \\
\hline $\begin{array}{c}\text { Gilabert- } \\
\text { Estellés }\end{array}$ & 2007 & Caucasian & MMP-3 & 111 & 50 & $\begin{array}{c}\text { Tissue- } \\
\text { Extracts }\end{array}$ & $\begin{array}{c}.078+/-.058 \\
\text { (MMP-3 mRNA) }\end{array}$ & $\begin{array}{c}.018+/-.006 \\
\text { (MMP-3 mRNA) }\end{array}$ \\
\hline
\end{tabular}

One study by Szamatowicz et al. set out to explore variations in MMP and TIMP levels in the peritoneal fluid of women with endometriosis. Women with endometriosis associated infertility were compared to a control group of infertile patients, and there was a concentration of $6.2+/-1.8 \mathrm{ng} / \mathrm{ml}$ in patients with endometriosis as compared to $2.9+/-2.6 \mathrm{ng} / \mathrm{ml}$ in the control group [3]. Furthermore, TIMP-1 levels in patients with endometriotic peritoneal fluids were found to have a statistically lower concentration than in the samples collected from the women in the control group. The lab concluded that "these results suggest that a disturbed equilibrium exists between MMP-9 and TIMP-1 in peritoneal fluid of women with endometriosis" which may be a contributing factor to the development of the disease [3].

Liu et al. also tested the levels of MMP-9 in serum and ascites samples of 100 patients and compared these levels to those of a control group. It was found that the endometriosis patients had a significant elevation in MMP-9 levels in both of these samples. Additionally, individuals with more advanced stages of the disease had even higher levels of MMP-9. The lab concluded that expression levels had a correlation with proliferation, endometrium site, and clinical stage of the disease. It is suggested that MMPs are "involved in the ectopic implantation and invasion of endometrium tissues, as it can facilitate the degradation of extracellular matrix and help the penetration of basal membrane" [4]. MMP-9, the member of the protein family studied by Liu et al. specifically degrades type III, type IV, and type V collagen and elastin along with allowing for neo-angiogenesis and an increase in blood flow which contribute to the "invasive growth of ectopic endometrium" [4]. Considering the finding that patients in the proliferative stage of the disease had significantly higher levels of MMP-9 expression compared to those in the beginning stages of endometriosis, this further exemplifies the role of the enzyme in allowing for the progression of endometriosis. This increase in MMP-9 levels has been found to have a correlation with pelvic inflammation since "the elevated MMP-9 levels in the patients' peritoneal fluids is mainly due to the high percentage of local macrophages" which are responsible for the inflammation [4].

A similar study by Durmus et al. explored the levels of MMP-9 in women with endometriosis. Serum MMP-9 levels were measured in a group of 60 patients and were compared to a control group consisting of 31 women. It was found that "MMP-9 levels were significantly higher in the study group compared to the controls," and additionally, "MMP-9 might be a potential predictive marker for advanced stages of the disease" [5]. The lab notes that MMP9 levels are higher in eutopic/ectopic endometrial tissue and they promote the invasion of endometriotic lesions. It also appears that another protein, NGAL, forms a complex with MMP-9 to inhibit antidegradation. The authors stated that the "MMP-9 cut-off level for prediction of severe endometriosis is a novel finding obtained from this study with acceptable sensitivity and specificity" [5].

Studies have also been done regarding the expression of MMP-2. It has been found that women with endometriosis have higher levels of MMP-2 [6]. This study by Huang et al. found that 
in a group of 40 patients with endometriosis, peritoneal fluid and serum levels of MMP-2 were elevated and levels of progesterone were lower as compared to a control group, and these "results demonstrated a correlation between MMP-2 concentrations and steroid hormones in sera and peritoneal fluids of the patients with endometriosis-associated infertility." Moreover, it is suggested that progesterone is responsible for the downregulation of MMP2 "to inhibit the formation and development of endometriosis" [6]. Malvezzi et al. note in their study that "levels of MMP-2 were significantly higher in the serum of infertile women with advanced stages of endometriosis," so this may indicate that "advanced pelvic endometriosis severity is related to higher serum MMP-2 levels" [7].

Another lab which studied the MMP-3 expression levels in women with endometriosis compared 71 samples to 50 controls and found a positive correlation between elevated MMP-3 levels and endometriosis [8]. They conclude that "the development of endometriotic implants at ectopic sites may be facilitated" by this elevation in MMP-3, "promoting the progress of the endometriosis" [8]. Sayantan et al. studied the specific mechanism of MMP-3 in the progression of endometriosis by focusing on MMP-3 and the apoptotic pathway. They "speculate that increased MMP-3 activity might be involved in the Fas mediated apoptosis" [9]. They utilized the mouse model and found "endometriotic developments" with "increased MMP-3 expression" as well as "TUNEL positive cells" which "might have resulted from destruction of local immune cells" [9].

\section{Progesterone Resistance and MMPs}

In the review by Balkowiec et al. it was found that although MMP expression is controlled by various inhibitors such as RECK and TIMP, "steroid hormones were described as main agents, that have an influence on MMPs activity, especially in endometriosis and endometrial tissue turnover" [11]. A recent study published in 2019 found that an imbalance in the ratio of two different progesterone receptors, PR-A and PR-B, may affect the gene expression of MMP-2 and MMP-9 which could lead to the development of endometriosis. Normally, these MMPs allow for degradation of ECM for menstrual endometrial remodeling, but with this overexpression in women with endometriosis and a decreased amount of their inhibitors, TIMPs, "tumor invasion, fibrosis, and endometriosis" are likely to occur [10]. In women without endometriosis, progesterone is responsible for preventing the breakdown of the endometrium by inhibiting MMPs, but in women with endometriosis, it has been found that the endometrium is resistant to the normal effects of progesterone. These enzymes are resistant to suppression by progesterone in endometriosis, and therefore, this study aimed to find an association between the progesterone receptor ratio and MMP expression. The study determined that women with endometriosis have a statistically significant lower expression of PR-B as well as an over-expression of MMP-9. The researchers further concluded that this altered PR-B expression may be correlated with this MMP-9 overexpression.
Moreover, high levels of MMP-2 and MMP-9 along with low levels of TMP-1 may be responsible for "low production of mature oocytes and subsequent decreased quality of embryos in endometriosis patients," so these expression levels are potential causes of the infertility often associated with the disease. PR-B had a significantly decreased expression level in the experimental group, and when the ratio of the receptors is higher in PR-A, then there is an increase in expression of pro-inflammatory genes. Thus, the inflammatory symptoms of endometriosis may be due to this change in ratio of progesterone receptors. The lab's data also showed that the alteration in the PR-A/PR-B ratio may lead to MMP-9 overexpression.

Additionally, MMP-1, -2, -3, - -11, - -13, - -15, and -23 have been experimentally found to be expressed at higher levels in women with endometriosis. A 2004 study by Nap et al. used a chicken Cholorio Allantoic Membrane (CAM) model with human endometrium transplanted onto the CAM to study the levels MMP activity, and all of these MMPs had high expression profiles [11]. When these MMPs were inhibited, this "led to significant inhibition of endometriosis-like lesion formation in CAMs" which "indicates that MMPs are involved in endometriosis-like lesion development and that the CAM model is a useful tool to evaluate the involvement of MMPs in the initial steps of lesion formation and endometrial tissue" [11]. Before this study, it was not reported that MMP-8, -13, $-10,-15,-16$, and -23 were correlated to endometriosis. Therefore, it is possible that many subclasses of MMPs are responsible for the pathogenesis of this disease, however, the "results indicate functional involvement of MMP-1, -2, -3, -7 and -13 in this process," but other "MMPs or mechanisms cannot be excluded" [11].

\section{Selective Progesterone Receptor Modulators (SPRMs): Potential Treatment Option}

Selective progesterone receptor modulators (SPRMs) are a class of drugs which target progesterone receptors and can affect their expression. In 2018, a study concerning the effectiveness of various selective progesterone receptor modulators was published. All of these drugs have controversial usage and recurrence of endometriosis after use of these drugs were not studied before this experiment [12]. The study utilized mouse endometriosis models, and it was found that the drugs all "effectively limit the endometriotic lesion growth and development" by "inhibition of progesterone receptor and cell proliferation and activation of apoptosis mechanisms" [12]. It was also concluded that the side effects of the Dienogest in particular were not significant, indicating a wide safety margin.

There are additional types of SPRMs which have been reported to treat the symptoms associated with endometriosis. Mifepristone and asoprisnil "have been shown to significantly reduce menstrual blood loss in association with fibroids but do not increase proliferation," and the administration of these drugs in patients with endometriosis resulted in a reported decrease in symptoms. A clinical study involved the administration of Asoprisnil in patients 
with endometriosis resulted in a decrease in non-menstrual pelvic pain as well as dysmenorrhea as compared to a group that received a placebo [13]. With the administration of mifepristone, it was found that patients also reported a decrease in their symptoms including pelvic pain and uterine cramping [13].

\section{Conclusion}

MMPs have been found to have an association with the pathogenesis of endometriosis which shed light on narrowing the scope of future endometriosis research. Studies can begin to focus on specific the genes responsible for MMP expression and factors that may affect their abnormal expression in order to better understand the mechanisms of the disease [14]. This will aid in the development of a novel method for non-invasively identifying endometriosis as well as serve as a starting point for the potential use of drugs like SPRMs as treatment methods [15].

Some limitations of the studies mention include the unknown involvement of other classes of MMPs as well as the lack of larger experimental groups or the use of animal models when studying the use of SPRMs which may not reflect certain side effects in humans. Therefore, although these experimental findings provide for a good starting point for further research concerning MMPs and their role in endometriosis as well as the potential use of SPRMs, more research must be done in order to solidify the knowledge surrounding MMPs and the pathogenesis of endometriosis as well as to determine the safety of using these drug treatments.

\section{References}

1. Osteen KG, Yeaman GR, Bruner-Tran KL (2003) Matrix metalloproteinases and endometriosis. Thieme 2(21): 155-164.

2. Bałkowiec M, Maksym RB, Włodarski PK (2018) The bimodal role of matrix metalloproteinases and their inhibitors in etiology and pathogenesis of endometriosis (Review). Mol Med Rep 18(3): 31233136.

3. Szamatowicz J, Laudański P, Tomaszewska I (2002) Matrix metalloproteinase-9 and tissue inhibitor of matrix metalloproteinase-1: a possible role in the pathogenesis of endometriosis. Hum Reprod 17(2): 284-288.

\section{ISSN: 2574-1241}

DOI: 10.26717/BJSTR.2019.21.003636

Bhuchitra Singh. Biomed J Sci \& Tech Res

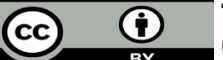

This work is licensed under Creative

Commons Attribution 4.0 License

Submission Link: https://biomedres.us/submit-manuscript.php
4. Liu H, Wang J, Wang H, Tang N, Li Y, et al. (2015) Correlation between Matrix Metalloproteinase-9 and Endometriosis. Int J Clin Exp Pathol 8(10): 13399-13404

5. Durmus BA, Cengiz DS, Yilmaz H, Candar T, Gursoy AY, et al. (2019) The levels of matrix metalloproteinase- 9 and neutrophil gelatinaseassociated lipocalin in different stages of endometriosis. J Obstet Gynaecol 39(7): 991-995.

6. Huang HF, Hong LH, Tan Y, Sheng JZ (2004) Matrix metalloproteinase 2 is associated with changes in steroid hormones in the sera and peritoneal fluid of patients with endometriosis. Fertil Steril 81(5): 1235-1239.

7. Malvezzi H, Aguiar VG, Paz CC, Tanus-Santos JE, Penna IA, et al. (2012) Increased Circulating MMP-2 Levels in Infertile Patients with Moderate and Severe Pelvic Endometriosis. Sage Journals 20(5): 557-562.

8. Gilabert-Estellés J, Ramón LA, España F, Gilabert J, Vila V, et al. (2007) Expression of angiogenic factors in endometriosis: Relationship to fibrinolytic and metalloproteinase systems. Hum Reprod 22(8): 21202127.

9. Jana S, Paul S, Swarnakar S (2012) Curcumin as Anti-endometriotic agent: implication of mmp-3 and intrinsic apoptotic pathway. Biochem Pharmacol 83(6): 797-804.

10. Mousazadeh S, Ghaheri A, Shahhoseini M, Aflatoonian R, Afsharian P (2019) The Effect of Imbalanced Progesterone Receptor-A/-B Ratio on Gelatinase Expressions in Endometriosis. Int J fertil steril 13(2): 127134.

11. Nap AW, Dunselman GA, de Goeij AF, Evers JL, Groothuis PG (2004) Inhibiting MMP activity prevents the development of endometriosis in the chicken chorioallantoic membrane model. Human Reproduction 19(10): 2180-2187.

12. Liang B, Wu L, Xu H, Cheung CW, Fung WY, et al. (2018) Efficacy, safety and recurrence of new progestins and selective progesterone receptor modulator for the treatment of endometriosis: A comparison study in mice. Reprod Biol Endocrinol 16(1): 32.

13. Chwalisz K, Perez MC, DeManno D, Winkel C, Schubert G, et al. (2005) Selective Progesterone Receptor Modulator Development and Use in the Treatment of Leiomyomata and Endometriosis. Endocr Rev 26(3): 423 438.

14. Cardoso JV, Machado DE, da Silva MC, Berardo PT, Ferrari R, et al. (2019) Matrix metalloproteinases 3 polymorphism increases the risk of developing advanced endometriosis and infertility: A case-control study. Eur J Obstet Gynecol Reprod Biol X 3: 10041.

15. Wagenfeld A, Saunders PT, Whitaker L, Critchley HO (2016) Selective progesterone receptor modulators (SPRMs): Progesterone receptor action, mode of action on the endometrium and treatment options in gynecological therapies. Expert opin ther targets 20(9): 1045-1054.

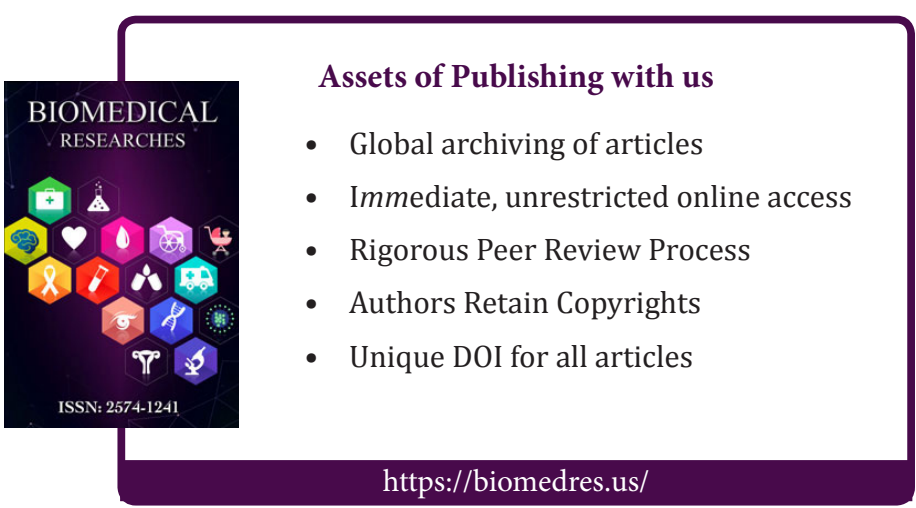

Copyright@ Bhuchitra Singh | Biomed J Sci \& Tech Res | BJSTR. MS.ID.003636. 